\title{
Technology of Quick-Frozen Flour Fish Culinary Products
}

\author{
Valentina Pavlova ${ }^{1 *}$, Irina Saenkova ${ }^{2}$, Yulia Shokina1, and Grigoriy Shokin ${ }^{1}$ \\ ${ }^{1}$ Institute of Natural Science and Technology, Department of Food Production Technology, the \\ Murmansk State Technical University, Murmansk, Russian Federation \\ ${ }^{2}$ Institute of Natural Science and Technology, Department of Technological and Refrigerating \\ Equipment, the Murmansk State Technical University, Murmansk, Russian Federation \\ ORCID
}

Valentina Pavlova: 0000-0002-6513-1912

Corresponding Author: Valentina

Pavlova; email:

pavlovavv@mstu.edu.ru

Dates

Published 13 January 2022

Publishing services provided by

Knowledge E

(c) Valentina Pavlova et al. This article is distributed under the terms of the

Attribution License, which

permits unrestricted use and redistribution provided that the original author and source are credited.

Selection and Peer-review under the responsibility of the 8th Scientific and Practical Conference Conference Committee.
Abstract. In this article, the results of the development of the functional fish culinary product "Thorny Skate and Cod Pie" are presented. A traditional recipe was used for making the yeast dough for the pie. The pie filling recipe was designed using Fuzzy Logic in the Matlab software package.Optimized parametersfor the selected sensory evaluation of the pie were calculated. On the basis of a priori information, key components of the filling (including the fraction of the fish components and skate meat) were chosen as the factors of interest. According to the simulation results, the optimal values werea 50/50 percentage for the first and the second factor respectively, and this providedthe maximum organoleptic assessment (five points on a five-point scale). The simulation results were compared with the results of the organoleptic evaluation of the pie made according to the optimized recipe, and their sufficient convergence was shown. The indicators of mass fraction of amine nitrogen and nitrogen of volatile bases was studied, as well as the microbiological safety indicators of flour fish culinary products, in accordance with the requirements of the Technical Regulations of the Eurasian Economic Union 040/2016 "On the safety of fish products". The results showed a high efficiency of the shock freezing of the semi-finished product, brought to semi-readiness, for long-term storage (120 days at a temperature no higher than minus $18{ }^{\circ} \mathrm{C}$ ), without reducing the quality or safety of the pie. The product had a cholesterol content from 220 to $260 \mathrm{mg} \%$, which allowed it to be classified as functional. The nutritional values of the product (mass fraction of protein, fat, carbohydrates, and amino acid composition) are presented.

Keywords: thornyskate, functional product, pie with thornyskate and cod, shock freezing

\section{Introduction}

In recent years, the problem of processing concurrent by-catch for bottom fish (mainly cod) in the Barents sea has become more urgent. PINRO studies have shown that the main share in such by-catches is accounted for by stingrays and skates [1, 2]. They are cartilaginous fish with a high content of full-fledged protein (from 16 to $20 \%$ by weight of the edible part), high content of chondroitin sulfate (CS) and urea [3]. The latter circumstance makes it difficult to process skates for food purpose, and the lack 
of a tradition of eating dishes made from skates in Russia requires a well-thought-out strategy for bringing products from them to the market.

The earlier proposed technological solution to the problem of high content of urea in the muscle tissue of the thorny skate, which consists in applying preliminary heat treatment to cut raw materials, namely blanching of the skate wings in water temperature between 94 to $96{ }^{\circ} \mathrm{C}$ at a ratio of fish:water 1:2 for 1 minute. The effectiveness of the method has been proved by experiments that confirmed a decrease in the mass fraction of urea by $74-86 \%$ of the initial content (when calculating the efficiency, the mass loss of the semi-finished product is taken into account from 8 to $11 \%$, depending on the specific surface of the wings) [4]. However, a semi-finished product that has undergone a harsh preliminary heat treatment changes its functional and technological properties, which requires a special choice of further processing technology. The production of fish culinary flour products seems to be one of the most suitable ways to use heat-treated skate meat.

When choosing a specific technology for making culinary products, it is necessary to take into account, first of all, current market trends and consumer preferences. Currently, there is an increase in popularity among consumers of fish culinary products and semifinished products of a high degree of readiness, including frozen ones. Along with these trends, consumer demand is growing for functional, enriched and dietary products aimed at maintaining human health and preventing the most common diseases caused by the peculiarities of the modern human lifestyle such as obesity, diseases of the gastrointestinal tract, cardiovascular system and musculoskeletal system.

Taking into account the above, the actual goal of the research is to develop a recipe and technology for a functional fish culinary product using skate meat.

\section{Methods and Equipment}

\subsection{Methods}

\subsubsection{Organoleptic methods}

The determination of organoleptic properties was carried out by means of extended degustation by specialists using the developed scales. After statistical processing, the results of degustation were presented in the form of profiling programs. 


\subsubsection{Physic-chemical methods}

- mass fraction of water, fat and mineral matter - by weight method;

- mass fraction of total nitrogen (TN) and nonprotein nitrogen (NN) were determined

by Kjeldal method on Selecta Bloc Digest apparatus and Pro-Nitro A unit; before mineralization in the sample, trichloroacetic acid (TCA) protein deposition was carried out on $\mathrm{NN}$ with subsequent filtration;

- protein content in fish was found by multiplying the difference between TN and NN by 6,25 ;

- mass fraction of amine nitrogen - by distillation of free and bound volatile baseswith steam and subsequent interaction of the formed ammonia with sulfuric acid, the excess of which is titrated with alkali;

- mass fraction of amine nitrogen - by formalin titration, based on binding of amino groups with formalin and indirect determination of their amount based on the results of titration of carboxyl groups;

- mass fraction of carbohydrates - by calculated method;

- mass fraction of urea - by spectrophotometric method after color-forming reaction of urea in the water extract from the product (after the deposition of TCA proteins in it), with flame retardant in acidic medium in the presence of diacetylmonooxime;

- mass fraction of chondroitin sulfate (CS) was determined by the Dichet spectrophotometric method, which is based on the colored reaction of uric acids with carbazole; the amino acid composition of the finished product protein is based on high-performance liquid chromatography;

- digestibility of protein was determined by accelerated method of Jaramillo.

\subsubsection{Microbiological methods}

Safety indicators were determined in accordance with the regulatory documents of the Russian Federation (Technical Regulations of the Eurasian Economic Union TR EAES 040/2016) by standard methods.

\subsubsection{Mathematical methods}

The results of the experiments were processed using standard statistical methods via the Excel program, the optimal recipe composition of fillings pie with Thorny Skate and 
cod was determined using the Fuzzy Logic Toolbox module included in the MatLab package [5].

\section{Results}

The technology of making a pie includes basic operations such as preparing yeast dough in a way that does not imply the using of stiff ferments, cutting and forming the dough billet, preparing the pie filling, which includes a fish component, raw potatoes cut into thin plates, butter, onion cut into half rings, salt, ground black pepper. The dough piece is combined with the filling, a pie is formed, aged and baked at a temperature of 180 to $220^{\circ} \mathrm{C}$ until ready. The finished product is cooled, packed in a cardboard box, labeled and sold within 24 hours from the date of manufacture.

It is also possible that the pie is produced in a technological way, which implies prolongated shelf life. In this case the pie is baked until soft, then cooled and subjected to shock freezing to a temperature in the center of the pie not above minus $18{ }^{\circ} \mathrm{C}$, then stored at the same temperature. The fish component of the pie filling includes thorny skate wing meat and cod fillet with skin, cut into small pieces. Cod is included in the fish component in order to gradually introduce a fish that is unusual for the Russian consumer in the form of a traditional and more familiar fish pie with a traditional and favorable filling (in this case, cod). Tasting skate meat in a pie in combination with cod, the consumer will eventually be ready to purchase flour culinary productswith fish filling exclusively made from skate. In addition, the partial replacement of Atlantic cod pie filling with skate meat reduces the cost of the product.

Computer-aided design and optimization of the recipe composition of a pie filled with skate and cod was carried out according to the criterion of achieving the highest organoleptic evaluation of the finished product. The optimization parameter (output variable) is the organoleptic evaluation of the pie. The influencing factors (input variables) defined: the contents of the components in the fish pie filling, \% of the total weight of the filling; the content of skate in the fish component of the pie filling, \% on the total weight of the fish components in the filling of the pie. The area of the factor space is bounded by taking into account a priori information. The characteristics of the experiment plan are presented in table 1. To establish the relationship between the input variables and the optimization parameter, a series of 9 experiments describing various combinations of two influencing factors was carried out. Based on the results of the experiments, 9 rules that formed the knowledge base ("Rules" hereinafter) were formulated.

Visualization of fuzzy output in MatLab is shown in Figure 1. 
TABLE 1: Main characteristics of the experiment

The first input variable is the mass fraction of the fish component in the pie filling, $\%$ of the total mass of the filling Value range from 30.0 to 70.0 The number of linguistic terms is 5

The second input variable is the mass fraction of the thorny skate in the fish component of the pie filling, \% of the tota mass of the fish component

Value range from 25.0 to 75.0 The number of linguistic terms is 5

Output variable - organoleptic rating, points

Value range from 4.0 to 5.0 The number of linguistic terms is 5

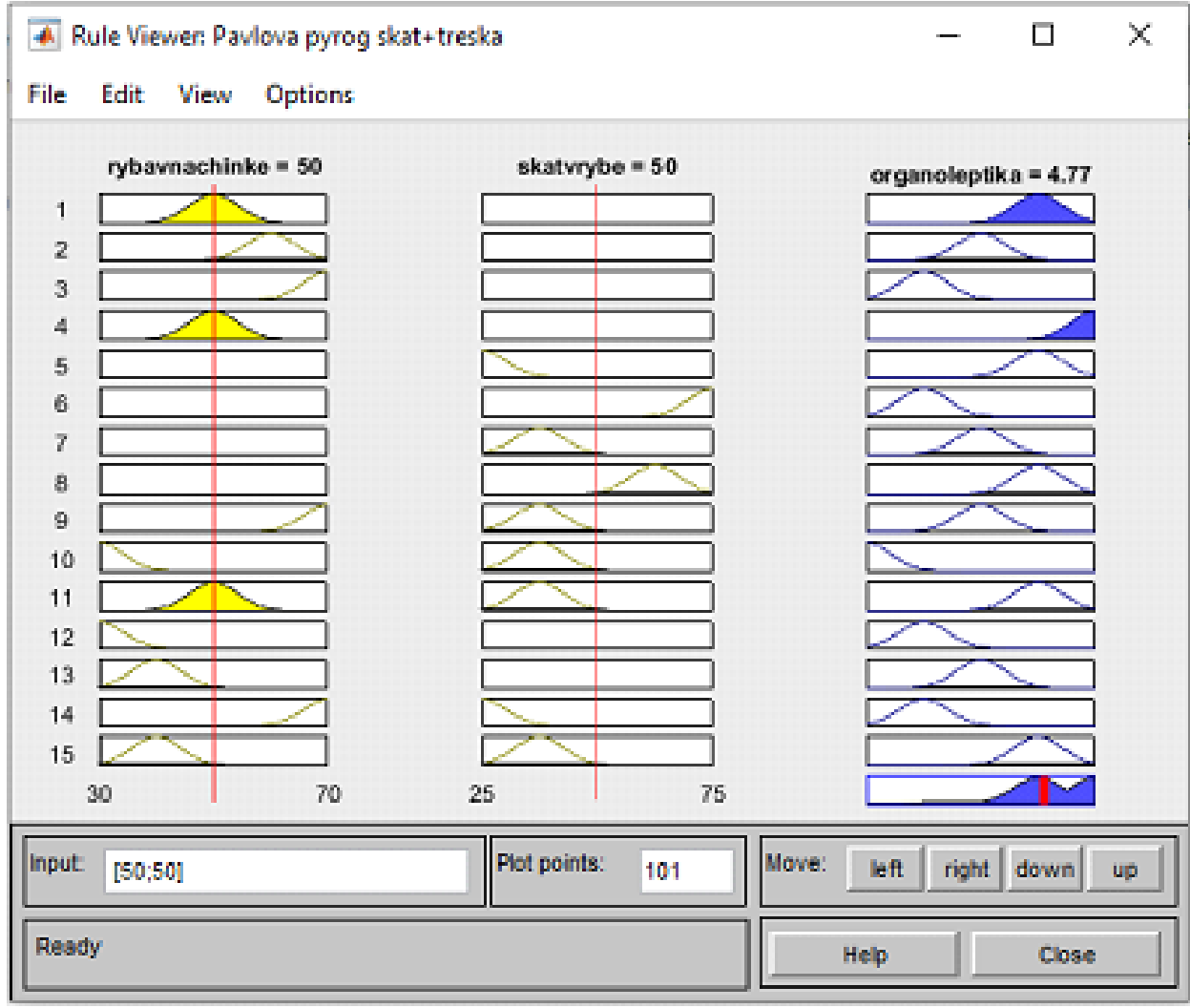

Figure 1: Visualization of fuzzy logical result inRuleViewer.

Figure 1 shows the progress of logical inference for each of the Rules, obtaining the resulting fuzzy set, and performing the defuzzification procedure. The resulting model determines the optimal values of the selected influencing factors - the key components of the recipe, namely, the share of the fish component in the pie filling - $50 \%$, the share of the skate in the fish component of the pie filling - $50 \%$. The control experiment performed for the values of influencing factors obtained by modeling showed high convergence of the model and the real technological process. 
TABLE 2: Chemical composition, energy value and digestibility of $100 \mathrm{~g}$ of the product «Thorny Skate and Cod pie»

Weight fraction, $\%$
Water 50,37
Total nitrogen 1,65
Non-protein nitrogen 0,10
Protein 9,69
Fat 5,14
Carbohydrates 32,85
Ash (the mineral matter) 1,95
Chondroitinsulfate, mgper $100 \mathrm{~g}$ of product 270
Energyvalue, kilocalories 216,4
Digestibility of protein $73,6 \%$

TABLE 3: Amino acid composition of the product «Thorny Skate and Cod pie» protein.

\begin{tabular}{l|l|l|}
\hline Amino acid & Weight fraction of amino acid \\
\hline inthe protein, \% & in the product, mg/100r \\
\hline Aspartic & 6,39 & 735 \\
\hline Glutamic & 28,04 & 3225 \\
\hline Serine & 6,27 & 721 \\
\hline Histidine & 4,97 & 572 \\
\hline Glycine & 6,63 & 762 \\
\hline Threonine+ GalN & 4,50 & 517 \\
\hline Arginine+ GaIN & 5,07 & 583 \\
\hline Alanine & 5,21 & 599 \\
\hline Tyrosine & 2,63 & 302 \\
\hline Valine & 3,85 & 443 \\
\hline Methionine & 2,97 & 342 \\
\hline Tryptophan & 0,15 & 17 \\
\hline Isoleucine & 4,20 & 483 \\
\hline Phenylalanine & 3,46 & 398 \\
\hline Leucine & 5,09 & 586 \\
\hline Lysine & 4,56 & 535 \\
\hline Total & 94,0 & 10810 \\
\hline
\end{tabular}

The results of the study of the total chemical composition and determination of the mass fraction of CS are presented in table 2 . Table 3 shows the amino acid composition of the product.

To prolong the shelf life of the pie, shock freezing and air freezing were applied with an average speed of the semi-finished productbrought to half-readiness. The preliminary shelf life of the frozen pie was 6 months. For its hygienic justification, complex studies of organoleptic, biochemical, microbiological changes in the product during 


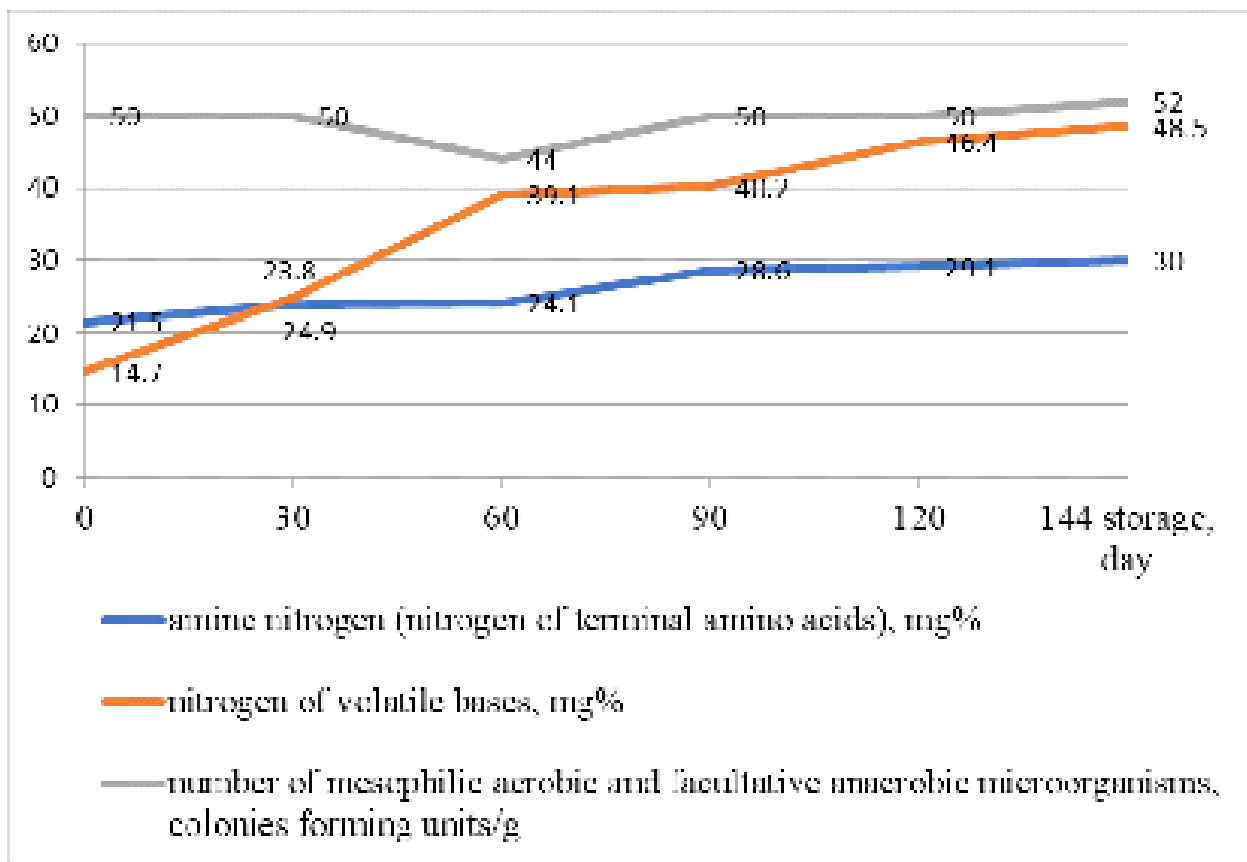

Figure 2: Results of research of biochemical and microbiological changes in the shock-frozen product «Thorny Skate and Cod pie» during storage at a temperature not higher than minus 18 degrees Celsius.

low-temperature storage were carried out in accordance with developed schedule $0^{\text {th }}, 30^{\text {th }}, 60^{\text {th }}, 90^{\text {th }}, 120^{\text {th }}$ and $144^{\text {th }}$ days (taking into account the reserve coefficient of 1.2) [6].

Biochemical changes in the pie during storage were evaluated by the mass fraction of amine nitrogen and nitrogen of volatile bases. The results are shown in Figure 2.

The figure shows that the increase in the amine nitrogen index in the pie after shock freezing occurs smoothly, the value of about $30 \mathrm{mg} \%$ is reached only by the $90^{\text {th }}$ day of storage. In parallel, similar experiments were performed with a pie after air freezing at an average speed. The value of the mass fraction of amine nitrogen in the control experiment reached $45 \mathrm{mg} \%$ by 15 days of storage.

The index of nitrogen of volatile bases in the pie after shock freezing during 60 days of low-temperature storage increased to about $40 \mathrm{mg} \%$ (Fig. 2), after which it stabilized until the onset of 90 days of storage. In the control experiment, by 72 days of storage, the indicator reached $40 \mathrm{mg} \%$, gradually increasing throughout the study period.

Based on the above, we conclude that the biochemical changes are similar in the shock-frozen pie and in the control sample-the air-frozen pie with an average speed. However, we observe a significant inhibition of proteolysis in the shock-frozen pie compared to the pie after air-freezing at an average speed. There is also a significant slowdown in microbiological processes, as evidenced by the nature of changes in the volatile base nitrogen index and the number of mesophilic aerobic and facultative 


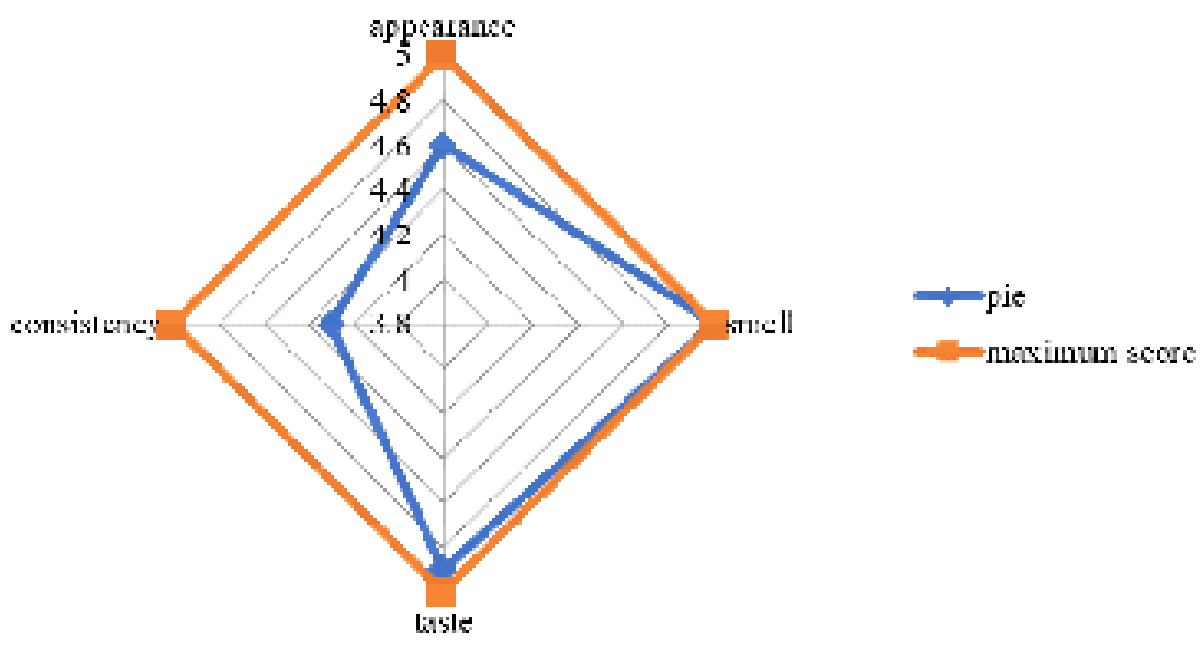

Figure 3: Change in the organoleptic evaluation of shock-frozen pie in points for individual indicators, without taking into account the weighting coefficients of individual indicators on the $120^{\text {th }}$ day of lowtemperature storage.

anaerobic microorganisms (NMAfAnM). Figure 2 shows that the value of the NMAfAnM index on the $90^{\text {th }}$ day of storage is three orders of magnitude less in a shock-frozen pie compared to air-frozen pie with an average speed. No pathogenic microorganisms were detected in all the studied samples during the entire study period. Mold and yeast grew more actively in the air-frozen product (from 20 cells per Petri dish for 15 days of storage to 100 cells by the day 72). In the shock-frozen product, cell growth was absent for 120 days of storage.

Organoleptic evaluation of pies was performed at the beginning and end of the expected shelf life (the background and $120^{\text {th }}$ day). The tasting showed a slight decrease in the product quality level to $92-95 \%$. The change in the organoleptic rating of the pie after shock freezing and low-temperature storage on the $120^{\text {th }}$ day is shown in Figure 3 as a profilogram.

As seen in Fig. 3, the decrease in the total score was due to a decrease in the rating of "consistency" indicator within 0.7 points, and "appearance" indicator less than 0.5 points.

\section{Discussion}

The recipe of a new functional fish culinary product "Thorny Skate and Cod pie" was designed. The search for the optimal ratio of the components of the product formulation 
was performed using an automated procedure - the method of fuzzy logical inference in the MatLab software package.

Analysis of the data in tables 2-3 allows to make a reasonable conclusion about the high nutritional value of the developed fish flour culinary product. The content of 270 $\mathrm{mg}$ of $\mathrm{CS}$ in $100 \mathrm{~g}$ of pie corresponds to $38 \%$ of the recommended level of adequate consumption of this compound. Thus, an unambiguous conclusion about the functional properties of the new product from the thorny skate can be drawn.

The result of a comprehensive study of biochemical, microbiological and organoleptic changes in pies is experimentally confirmed safety and high quality of the product after shock freezing and long-term low-temperature storage for 6 months at a temperature not higher than minus $18^{\circ} \mathrm{C}$ and a relative humidity of at least $96 \%$.

\section{Conclusion}

The technology of a new fish culinary product "Thorny Skate and Cod pie" for mass consumption is proposed. Due to the use of skate wing meat as a raw material, a high content of chondroitin sulfate in the finished product is achieved $100 \mathrm{~g}$ of the product contains more than $30 \%$ of the recommended level of adequate consumption of the substance). Chondroitin sulfate determines the chondroprotective functional properties of this new product [7-9]. Due to a presence of cod in the pie recipe, a successful launch of a product with skate, for which there is no stable tradition of consumption, will be ensured. Shock freezing of a semi-finished pie with subsequent storage at a temperature no higher than minus $18{ }^{\circ} \mathrm{C}$ is an effective way to extend the shelf life of a new product to 6 months, which is proved by the results of a comprehensive study of organoleptic, biochemical and microbiological changes.

\section{Funding}

This work was supported by the State task «Development of technology for fish and combined functional food products from underused fishing objects in the Arctic zone and hardware design» of the Federal state budgetary educational institution of higher education «Murmansk state technical University (MSTU)».

\section{Conflict of Interest}

The authors have no conflict of interest to declare. 


\section{References}

[1] Grekov AA.Bottom longline fishery in the Barents sea and adjacent waters.Murmansk: PINRO Press; 2012.

[2] Preliminary materials of total allowable catch in the area of extraction of aquatic biological resources in inland sea waters of the Russian Federation for 2020. FSBNU VNIRO (PINRO). 2019/18/7 Available from: http://www.pinro.ru/19//

[3] Korchunov VV.Development of the food technology for thorny skate species [Doctoral Thesis]. Russia, Murmansk, Murmansk State Technical University; 2004.

[4] ShokinaYV, ShtetinskiyVV, Pavlova VV, Saenkova IV Justification of the modes of heat treatment of semi-finished product from thorny skate in the production of fish culinary products for functional purposes. Bulletin of Voronezh State University of Engineering Technologies. 2014;59(1):102-107.

[5] MuratovaEl, Tolstyh SG, Dvoteyskii SI, Zuzina OV, Leonov DV Automated design of complex multi-component food products.Tambov: TambovStateTechnicalUniversityPublishingHouse; 2011.

[6] Methodological instructions. 4.2.1847-04 Sanitary and epidemiological evaluation of justification of expiration dates and conditions of foodstuff storage. Electronic fund of legal and normative-technical documents. 2004-06-20 Available from:http://docs.cntd.ru/document/1200035982

[7] Krichen $\mathrm{F}$, Bougatef $\mathrm{H}$, Sayari $\mathrm{N}$ et al. Isolation, purification and structural characterestics of chondroitinsulfate from smooth hound cartilage: In vitro anticoagulant and antiproliferative properties. Carbohydrate Polymers. 2018;197:451-459.

[8] Krichen F, Volpi N, Sila A et al. Purification, structural characterization and antiproliferative properties of chondroitinsulfate/dermatan sulfate from Tunisianfish skins. International Journal of Biological Macromolecules. 2017;95:32-39.

[9] Miraglia N, Bianchi D, Trentin A et al. Safety assessment of non-animal chondroitinsulfate sodium: Subchronic study in rats, genotoxicity tests and human bioavailability. Foodand Chemical Toxicology. 2006;93:89-101. 